\title{
Modulation Excitation X-Ray Absorption Spectroscopy to Probe Surface Species on Heterogeneous Catalysts
}

\author{
Davide Ferri - Mark A. Newton - Maarten Nachtegaal
}

Published online: 13 August 2011

(C) Springer Science+Business Media, LLC 2011

\begin{abstract}
The advantages and open questions of the combination of modulation excitation spectroscopy and phase sensitive detection (PSD) with X-ray absorption spectroscopy (XAS) for the analysis of heterogeneous catalysts at work are reviewed. The characteristic spectral signatures of two different edges $\left(\mathrm{Pd} \mathrm{K}\right.$ and $\left.\mathrm{Pt}_{3}\right)$ are described in relation to the red-ox chemistry of $\mathrm{Pd} / \mathrm{Al}_{2} \mathrm{O}_{3}$ and $\mathrm{Pt} / \mathrm{Al}_{2} \mathrm{O}_{3}$ with respect to $\mathrm{NO}$ reduction by $\mathrm{CO}$ and $\mathrm{CO}$ oxidation, respectively. Both examples demonstrate that PSD makes XAS sensitive to potentially active species for the catalytic reaction.
\end{abstract}

Keywords X-ray absorption spectroscopy $\cdot$ Modulation excitation spectroscopy $\cdot \mathrm{Pd} \cdot \mathrm{Pt} \cdot \mathrm{NO}$ reduction $\cdot \mathrm{CO}$ oxidation

\section{Introduction}

The key principle of the operando methodology involves a spectroscopic experiment in which light is shined on a

Part of this work was presented at the 14th Nordic Symposium on Catalysis, 29-31 August 2010, Marienlyst, Denmark.

D. Ferri $(\bowtie)$

Laboratory for Solid State Chemistry and Catalysis, Empa, Swiss Federal Laboratories for Materials Science and Technology,

Ueberlandstrasse 129, Dübendorf 8600, Switzerland

e-mail: davide.ferri@empa.ch

M. A. Newton

European Synchrotron Radiation Facility, 6 Rue Jules Horowitz, 38043 Grenoble, France

M. Nachtegaal

Paul Scherrer Institute, Villigen 5232, Switzerland working catalyst while catalytic activity is simultaneously determined using adequate analytics within or downstream the reactor [1]. In the strictest definition, the spectroscopic cell should behave as close as possible to a real reactor [2]. The essential task of this methodology is to capture the relevant species for the process at the moment the catalytic event takes place. Therefore, this species should be spectroscopically evident and well separable from other species not relevant to the reaction. This task could be in principle fulfilled when surface sensitive spectroscopic techniques are applied (as for example the vibrational spectroscopies). Other widely spread operando techniques such as X-ray diffraction (XRD) and X-ray absorption spectroscopy (XAS) are typically 'bulk' sensitive methods. They probe structure directly but sample the entire volume and provide averaged structural information as a result; moreover, they do this in different, though often complementary ways. However, even in the case of surface sensitive methods, crucial species rarely present intense and clear signals; almost by definition reactive intermediates are short lived and therefore difficult to observe and separate from other spectroscopic signals using conventional steady state experiments.

A conventional experiment typically consists of sampling the catalyst structure while running a temperature ramp and keeping the sample under steady state conditions of reactants. This procedure is typically not able to distinguish between the components of the catalyst that are relevant to the reaction and those that are not. Subjecting the catalyst to pulses or fast transients is a more suitable approach to selectively obtain information about active species. Steady state isotopic transient kinetic analysis (SSITKA) employs the fast isotopic perturbation to probe the response of relevant species while a spectroscopic experiment is performed [3]. Moreover, it is known that the 
perturbation of the steady state conditions can drive the system to improved catalytic activity or stability [4-6]. A major example of this operation is that of a three-way catalyst whose atmosphere is continuously and rapidly changed between rich and lean around the stoichiometric value $(\lambda=1)$ [7]. Catalytic activity towards the abatement of the pollutants $\mathrm{NO}_{x}, \mathrm{CO}$ and hydrocarbons is thus maintained at optimal levels and the lifetime of the catalyst is extended. Therefore, from the viewpoint of the catalytic process, conducting the spectroscopic experiment under pulsed conditions can represent an important step towards a realistic operando approach as the catalyst is then analyzed under more genuine conditions. As introduced above, from the analytical viewpoint, pulsed experiments enable to better differentiate between active and spectator species as it becomes easier to observe the response of spectroscopic signals of active species compared to steady state conditions.

A special approach for pulse experiments is provided by modulation excitation spectroscopy (MES) [8]. The catalyst is perturbed by the continuous change of an external parameter (concentration, temperature, pressure, $\mathrm{pH}$, potential...) while the spectroscopic acquisition is made. A sine-qua-non condition is that the process under investigation is reversible. The time-resolved spectra collected during the experiment are first averaged over the number of pulse sequences. This procedure creates a new set of time-resolved spectra with obviously improved signal-to-noise ratio and reduces the amount of spectra to the number of spectra measured within a modulation period ( $T$, defined as the time required to conclude one pulse sequence). The use of the phase sensitive detection (PSD) analysis described by Eq. 1 is the essential 'novelty' of the method [8].

$A_{k}^{\phi^{\mathrm{PSD}}}(e)=\frac{2}{T} \int_{0}^{T} A(e, t) \sin \left(k \omega t+\phi_{k}^{\mathrm{PSD}}\right) \mathrm{d} t$

Equation 1 allows treating the time-resolved spectra in a different way [9]. A new set of spectra is obtained, the socalled phase-resolved spectra (or demodulated spectra), which have three basic, yet important, features. First, they present only signals of species which responded to the external stimulation with the same frequency. They therefore yield a massively enhanced sensitivity to species that ordinarily would produce small signals that are difficult to separate from the generally much larger static signals. Secondly, they exhibit higher levels of signal-to-noise ratio, because the noise has a different response frequency. For the same reason, static signals (typically overwhelming) are also cancelled. Third, in principle they allow better differentiation of signals with different kinetics.

MES has been used for heterogeneous catalysts almost exclusively associated to infrared spectroscopy [10-15]. However, it has the potential to provide additional power to other spectroscopic techniques, for example XAS [16]. Some XAS and XRD experiments of the type proposed by the MES approach have been reported [17-19], however, without application of the PSD analysis. A first step towards PSD was provided by Stötzel et al. who averaged the XAS spectra of $\mathrm{Pt}-\mathrm{Rh} / \mathrm{Al}_{2} \mathrm{O}_{3}$ over three modulation periods to demonstrate the improvement in the signal-tonoise ratio [20]. In a provocative way, it can be claimed that MES in combination with PSD can impart to XAS the sensitivity to surface and active species it needs for the analysis of heterogeneous catalysts under working conditions, within the terms indicated in the following. In this contribution, two examples are shown which demonstrate the potential of modulation excitation X-ray absorption spectroscopy (ME-XAS).

\section{Experimental}

The $2 \mathrm{wt} \% \mathrm{Pd} / \mathrm{Al}_{2} \mathrm{O}_{3}$ and $2 \mathrm{wt} \% \mathrm{Pt} / \mathrm{Al}_{2} \mathrm{O}_{3}$ catalysts were kindly provided by Umicore. The metal dispersion was 20 and $22 \%$, respectively, as determined by pulsed $\mathrm{CO}$ chemisorption. The corresponding average particle size was of ca. $5 \mathrm{~nm}$ in both cases.

Experiments were performed in energy dispersive-EXAFS (ED-EXAFS) and QuickEXAFS modes at the beamline ID24 of the ESRF (Grenoble, France) and at the SuperXAS beamline of SLS (Villigen, Switzerland), respectively.

Time-resolved ED-EXAFS spectra were collected at the $\mathrm{Pd}$ K-edge $\left(E_{0}=24.35 \mathrm{keV}\right)$ using a $\mathrm{Si}(311)$ polychromator crystal in Bragg configuration and a FReLoN CCD camera [16]. The sample bed provided a X-ray transmission path length through the sample bed of $5 \mathrm{~mm}$ mounted within a reactor system designed for combined transmission EXAFS/DRIFTS measurements [21]. The X-ray beam was vertically defocused (to ca. $300 \mu \mathrm{m}$ at the detector). Compensation for the scattering of the polychromatic beam by the majority material in the sample (i.e., the support) was ensured by mounting a suitable reference ( $2 \mathrm{wt} \% \mathrm{Rh} / \mathrm{Al}_{2} \mathrm{O}_{3}$ ) at the same focal length as the sample but outside the sample environment [22]. Dispersive-EXAFS spectra were collected using $100 \mathrm{~ms}$ of actual X-ray exposure. The overall time resolution achieved, including detector dead time of $1.6 \mathrm{~ms}$ per frame, was ca. $260 \mathrm{~ms}$ per spectrum repetition. Six 
5 vol\% $\mathrm{CO} / \mathrm{He}$ vs. 5 vol\% $\mathrm{NO} / \mathrm{He}$ sequences (66 s each pulse) were repeated. Ninety synchronous DRIFT spectra were collected during a modulation period by co-adding 3 spectra at $40 \mathrm{kHz}$ scanner velocity and $2 \mathrm{~cm}^{-1}$ resolution on a Bruker Optics IFS66 spectrometer [16].

Time-resolved QuickEXAFS spectra were collected at $1 \mathrm{~Hz}$ rate in the transmission mode at the $\mathrm{Pt}_{\mathrm{L}_{3} \text {-edge }}$ $\left(E_{0}=11.564 \mathrm{keV}\right)$ using an excentric $\mathrm{Si}(311)$ cam driven monochromator. A capillary reactor cell [23] was heated using a gas blower and was connected to a gas manifold. A thermocouple was installed between the reactor and the blower away from the X-ray beam. The catalyst was firmly fixed in the quartz capillary reactor $\left(\emptyset_{\mathrm{e}}=3 \mathrm{~mm} ; 70 \mathrm{mg}\right.$ sample, $50 \mathrm{~mL} / \mathrm{min}, \mathrm{GHSV}=\mathrm{ca} .70,000 \mathrm{~h}^{-1}$ ) between two quartz wool plugs. Two electrically activated valves positioned ca. $5 \mathrm{~cm}$ away from the reactor allowed to repeatedly and rapidly switch the gas atmosphere provided to the catalyst. For the $5 \mathrm{vol} \% \mathrm{CO} / \mathrm{He}$ vs. $5 \mathrm{vol} \% \mathrm{O}_{2} / \mathrm{He}$ sequences, each pulse was $60 \mathrm{~s}$ long and the sequence was repeated ten times.

The Pd and Pt foils were used for calibration. Where needed, spectra were energy calibrated background corrected and normalized using the WinXAS 3.1 software package [24]. A mass spectrometer (Omnistar, Pfeiffer) was installed at the exit of both reactor cells to monitor the exhaust gas online.

Catalyst powders were sieved to the $70-90 \mu \mathrm{m}(\mathrm{Pd} /$ $\left.\mathrm{Al}_{2} \mathrm{O}_{3}\right)$ and $50-100 \mu \mathrm{m}\left(\mathrm{Pt} / \mathrm{Al}_{2} \mathrm{O}_{3}\right)$ fraction. Prior to the concentration modulation experiments, $\mathrm{Pd} / \mathrm{Al}_{2} \mathrm{O}_{3}$ was reduced in flowing $5 \% \mathrm{H}_{2} / \mathrm{He}(80 \mathrm{~mL} / \mathrm{min})$ at $573 \mathrm{~K}$ for $30 \mathrm{~min}$. Pt $/ \mathrm{Al}_{2} \mathrm{O}_{3}$ was reduced in flowing $10 \mathrm{vol} \% \mathrm{H}_{2} / \mathrm{He}$ $(50 \mathrm{~mL} / \mathrm{min})$ at $673 \mathrm{~K}$ for $30 \mathrm{~min}$. Then, the flow was switched to He until the MS signals were stable and the modulation experiments were started by periodically admitting $\mathrm{NO}$ and $\mathrm{CO}$ (at $573 \mathrm{~K}$ ) or $\mathrm{CO}$ and $\mathrm{O}_{2}$ (at $463 \mathrm{~K}$ ) to the spectroscopic reactor cell for the given number of modulation periods.

After acquisition, the spectra were treated according to Eq. 1 using Matlab scripts.

The DRIFT spectra shown in this work were collected with a Vertex 70 spectrometer equipped with a reaction chamber (HVC-DRP2, Harrick) and a liquid nitrogen cooled MCT detector. The catalyst (ca. $50 \mathrm{mg}$ ) was loaded in the sample cup of the reaction chamber and was contacted with constant $50 \mathrm{~mL} / \mathrm{min}$ gas flow. The same set of switch valves used at the SuperXAS beamline for the QuickEXAFS experiment was installed in front of the cell. After reduction of $\mathrm{Pt} / \mathrm{Al}_{2} \mathrm{O}_{3}$ at $693 \mathrm{~K}$ in $5 \mathrm{vol} \% \mathrm{H}_{2} / \mathrm{Ar}$, the modulation experiment was started by alternately admitting $5 \mathrm{vol} \% \mathrm{CO} / \mathrm{Ar}$ and $5 \mathrm{vol} \% \mathrm{O}_{2} / \mathrm{Ar}$ at $463 \mathrm{~K}$. Within a single modulation period $(T=120 \mathrm{~s})$ hundred spectra were acquired by accumulating 5 scans at $80 \mathrm{kHz}$ scanner velocity and $4 \mathrm{~cm}^{-1}$ resolution.

\section{Results and Discussion}

\subsection{NO Reduction by $\mathrm{CO}$ on $\mathrm{Pd} / \mathrm{Al}_{2} \mathrm{O}_{3}$}

The first case study is the NO reduction by $\mathrm{CO}$ on reduced $2 \mathrm{wt} \% \mathrm{Pd} / \mathrm{Al}_{2} \mathrm{O}_{3}$. Experiments were performed using a cell designed for combined EXAFS-IR experiments [21] and detailed results are published elsewhere [16]. The average time-resolved spectra of the reduced catalyst during $\mathrm{CO}$ vs. NO pulsing (Fig. 1) show only minor changes in the whole energy range scanned by ED-EXAFS. Only subtle changes are visible around the whiteline. The first information that is obtained is that the state of Pd during the experiment did not change significantly from that obtained prior to the pulse sequences by reduction at $573 \mathrm{~K}$. Hence, Pd remained in an essentially reduced state over the whole experiment. Applying PSD (Eq. 1) to the time-resolved spectra immediately evidences the subtle changes experienced by the catalyst under these conditions. The obtained phase-resolved spectra shown in Fig. 2(a) provide only the signature of the spectral changes occurring during the experiment. All features that are not undergoing changes are eliminated. This is evident for example for the edge jump or background. Moreover, the spectra exhibit a typical second-derivative shape. Importantly, the amplitude of the signals is an order of magnitude smaller compared to that of the time-resolved spectra. The signal-to-noise ratio is drastically improved by spectra averaging using Eq. 1

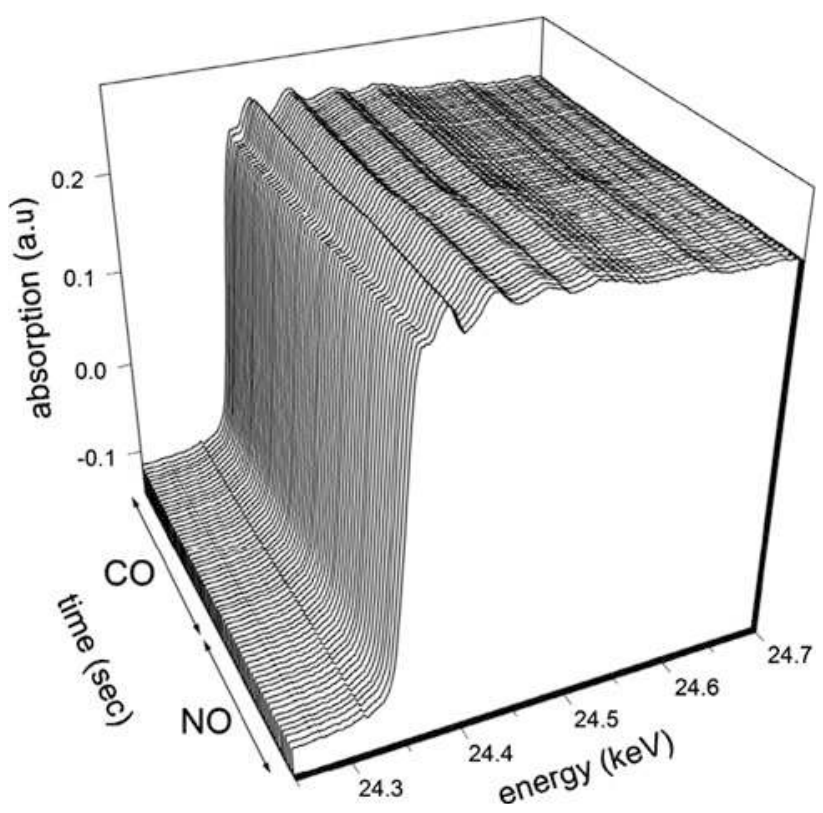

Fig. 1 Averaged time-resolved ED-EXAFS spectra collected at the Pd K-edge during the 5 vol\% CO vs. 5 vol\% NO modulation experiment on reduced $2 \mathrm{wt} \% \mathrm{Pd} / \mathrm{Al}_{2} \mathrm{O}_{3}$. Conditions: $573 \mathrm{~K}$, $T=132 \mathrm{~s}, 6$ modulation periods 

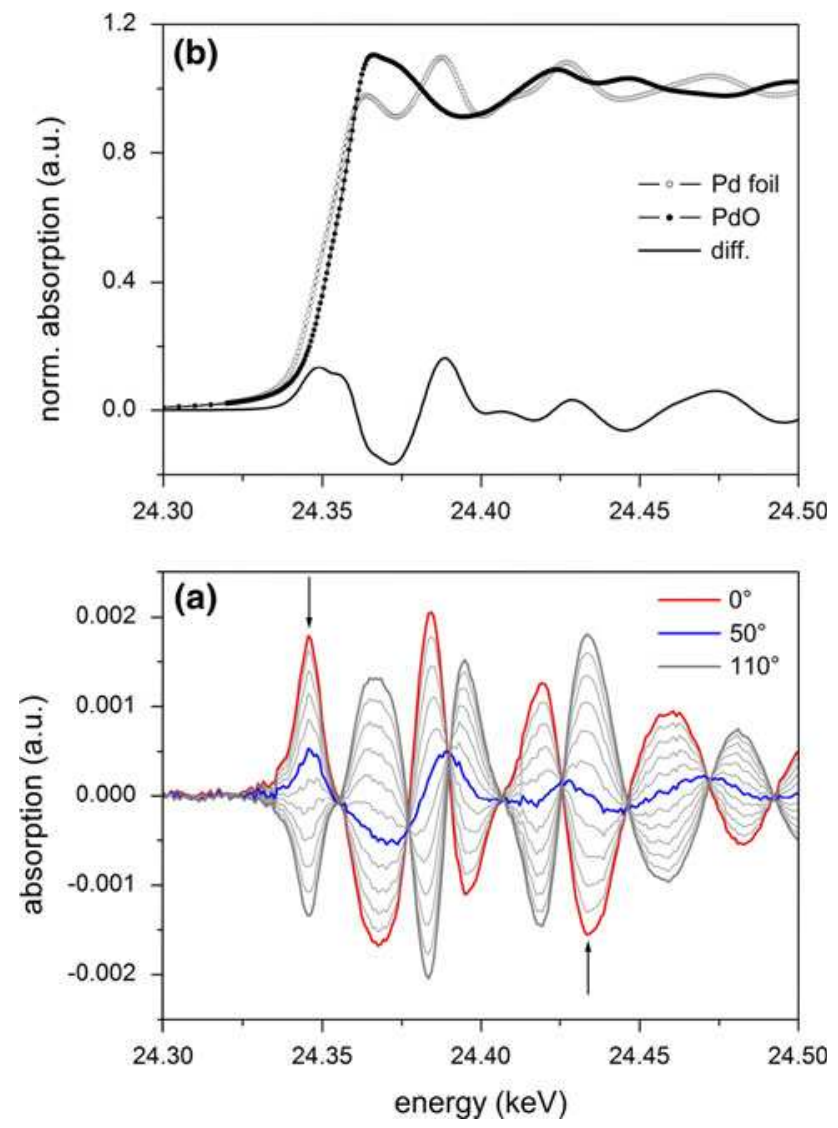

Fig. 2 a Phase-resolved spectra $\left(\varphi^{\mathrm{PSD}}=0-110^{\circ}\right)$ obtained from the 5 vol $\%$ CO vs. 5 vol\% NO modulation experiment on reduced $2 \mathrm{wt} \%$ $\mathrm{Pd} / \mathrm{Al}_{2} \mathrm{O}_{3}$. b The spectra of the $\mathrm{Pd}$ foil and of $\mathrm{PdO}$ are shown together with the difference spectrum $\mathrm{Pd}_{\text {foil }}-\mathrm{PdO}$ (diff.). The arrows indicate the signals for which the kinetic is extracted to Fig. 3

compared to a conventional difference spectrum, as shown for $\mathrm{Rh} / \mathrm{Al}_{2} \mathrm{O}_{3}$ under identical conditions [16].

The interpretation of the differential features of the phase-resolved spectra requires comparison with adequate reference spectra. Figure 2(b) shows XANES spectra of $\mathrm{PdO}$ and $\mathrm{Pd}$ (foil) references and the difference spectrum between these states. These are not necessarily the most appropriate references. The latter spectrum also exhibits the typical second-derivative like profile of difference spectra. Therefore, phase-resolved spectra are difference spectra with an improved signal-to-noise ratio. The difference spectrum of the reference states of Pd corresponds to the situation that should be expected if the catalyst would experience a 'simple' oxidation-reduction process. If the catalyst experiences only reduction-oxidation during $\mathrm{NO}$ reduction by $\mathrm{CO}$, the maxima and minima observed in the phase-resolved spectra should correspond to those of that difference spectrum. This is clearly not the case. It is easy to see in Fig. 2(a) that only the phase-resolved spectrum at $\varphi^{\mathrm{PSD}}=50^{\circ}$ resembles the reference difference spectrum, but only from ca. $40 \mathrm{eV}$ above the edge energy.
The other spectra exhibit the splitting of all signals except for the first two (ca. edge energy and $+10 \mathrm{eV}$ ). Something different than oxidation-reduction is seen in these spectra, that behaves differently upon switching the gases. The origin of these features cannot be deduced solely on the base of the spectra.

What PSD does through the improvement of the signalto-noise ratio is to allow the selection of signals in the phase-resolved spectra for which the kinetic over the modulation period can be extracted from the time-resolved spectra. This is extremely difficult for conventional difference spectra given their level of noise [16] and for signals far above the absorption edge where the signals are strongly damped. Figure 3 shows for example the temporal profile of the signal approximately corresponding to the edge energy and that of a signal at $+80 \mathrm{eV}$ (marked in Fig. 2a). Additionally, the response of the online MS is

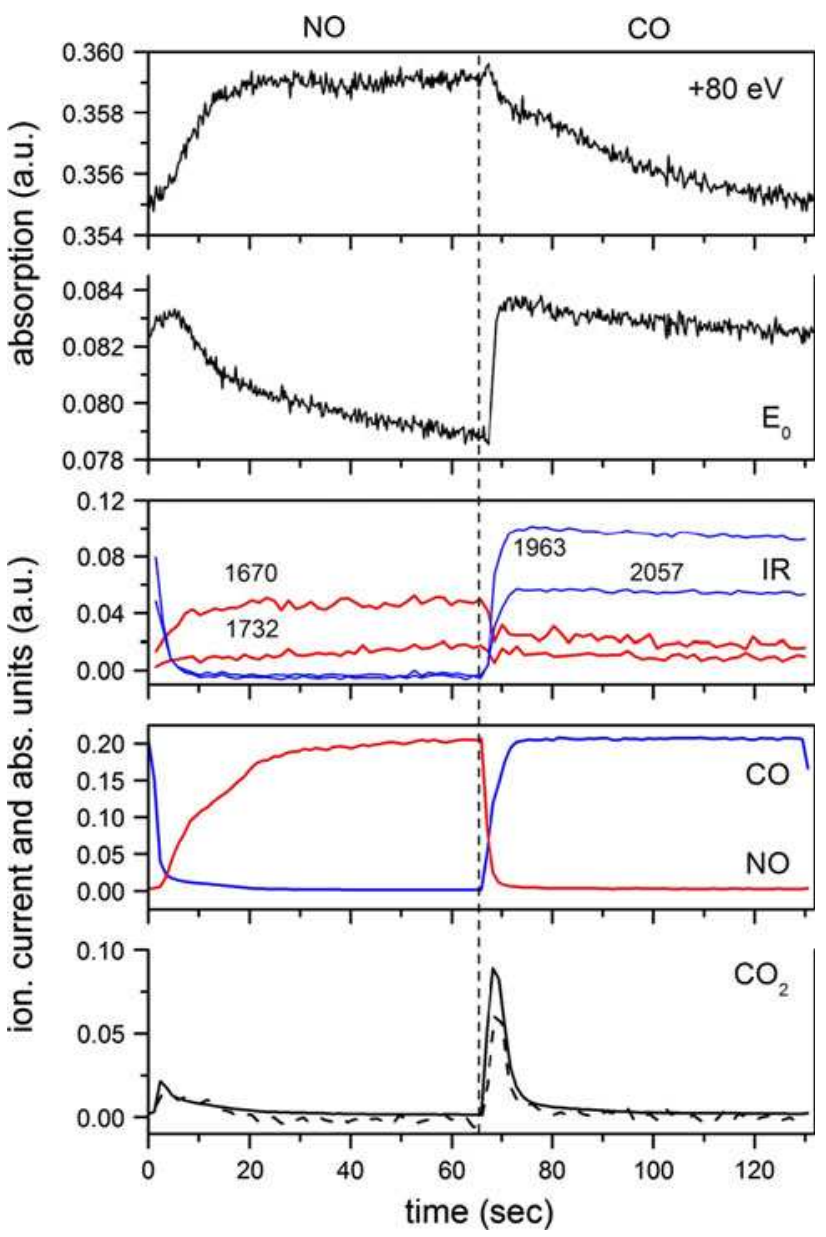

Fig. 3 Online MS response of $\mathrm{CO}, \mathrm{NO}$ and $\mathrm{CO}_{2}$, temporal evolution of IR signals in the synchronous DRIFTS experiment and of the signal corresponding to $E_{0}$ and at $+80 \mathrm{eV}$ selected from the phase-resolved spectra of Fig. 2 during the 5 vol\% CO vs. 5 vol\% NO modulation experiment on reduced $2 \mathrm{wt} \% \mathrm{Pd} / \mathrm{Al}_{2} \mathrm{O}_{3}$. The dashed profile in the $\mathrm{CO}_{2}$ panel represents the temporal response of the gas-phase $\mathrm{CO}_{2}$ signal in the DRIFTS experiment 
plotted for the reactants ( $\mathrm{CO}$ and $\mathrm{NO}$ ) and the product $\left(\mathrm{CO}_{2}\right) . \mathrm{N}_{2}$ overlaps with the $\mathrm{m} / \mathrm{e}=28$ signal of $\mathrm{CO}$. Selected signals from the DRIFT spectra [16] are also depicted. The signal corresponding to the edge energy readily intensifies at the $\mathrm{NO} \rightarrow \mathrm{CO}$ switch and stabilizes after ca. $10 \mathrm{~s}$ under $\mathrm{CO}$. At the $\mathrm{CO} \rightarrow \mathrm{NO}$ switch, the attenuation of the signal is considerably slower. An initial maximum ca. $5 \mathrm{~s}$ after the switch is observed that is followed by the slow intensity decrease. Since the signal can be roughly associated with the edge energy position, its growth indicates higher extent of reduction and its attenuation the extent of oxidation. Therefore, the observed profile reveals that the kinetic of re-oxidation is slower compared to the kinetic of reduction [25]. By comparison of the amplitudes of the signal at ca. $+10 \mathrm{eV}$ in the difference spectrum of the reference states and in the phaseresolved spectra of Fig. 2(a), it can be concluded that ca. $0.6 \%$ of palladium re-oxidizes.

The infrared signals corresponding to adsorbed NOrelated species warrant the slow oxidation of $\mathrm{Pd}$ under the $\mathrm{NO}$ pulse, whereas at the $\mathrm{NO} \rightarrow \mathrm{CO}$ switch the carbonyl signals (linear, $2057 \mathrm{~cm}^{-1}$; twofold, $1963 \mathrm{~cm}^{-1}$ ) quickly appear. It should be observed how the temporal response of the IR signals tightly follows that of the XAS signals from the phase-resolved spectra, therefore, supporting the processes captured by MES. In particular, the signal at $1670 \mathrm{~cm}^{-1}$ of Pd-nitrosyl species [26, 27] closely follows the signal at $+80 \mathrm{eV}$, whereas, the signals of adsorbed $\mathrm{CO}$ are obvious evidence of $\mathrm{Pd}$ reduction. Furthermore, the signal at $1732 \mathrm{~cm}^{-1}$ of linear Pd-NO follows the slow oxidation process shown by the edge energy signal $\left(E_{0}\right.$ in Fig. 3) thus intensifying till the conclusion of the NO pulse. This species may therefore contribute to $\mathrm{N}-\mathrm{O}$ dissociation and the formation of the oxidic layer seen by the phase-resolved spectra.

The signal at $+80 \mathrm{eV}$ exhibits a clearly different behaviour, which is mirrored by all other signals above the edge energy (see Ref. [16]). At the NO $\rightarrow$ CO switch, the signal diminishes slowly until the conclusion of the $\mathrm{CO}$ pulse. At the $\mathrm{CO} \rightarrow \mathrm{NO}$ switch, it gains intensity within ca. $20 \mathrm{~s}$ and stabilizes until the end of the pulse. Comparison with the online MS signals reveals that at the $\mathrm{NO} \rightarrow \mathrm{CO}$ switch a major signal of evolved $\mathrm{CO}_{2}$ is observed within the $10 \mathrm{~s}$ it takes to stabilize the signal corresponding to the edge energy.

We have shown that the slow increase of the signal at $+80 \mathrm{eV}$ under the $\mathrm{CO}$ pulse perfectly matches the slow increase of the Pd-Pd interatomic distance determined by fitting some 100 ED-EXAFS spectra in the conventional EXAFS approach [16]. Under the CO pulse the Pd lattice undergoes expansion that is interpreted with the formation of $\mathrm{PdC}_{x}$. These data have been supported by independent
hard-XRD experiments under similar conditions [18] and agree with other reports [28, 29].

Analysis of the two EXAFS signals of Fig. 3 and of the other ones [16] reveals that at least two processes are occurring in parallel, the partial reduction-oxidation of $\mathrm{Pd}$ and the formation-decomposition of $\mathrm{PdC}_{\mathrm{x}}$.

It is clear from this example that the features obtained in the phase-resolved spectra still need to be accurately understood if they are different from conventional oxidation-reduction processes. However, it is shown how MES enhances the level of information obtained by measuring under pulsed conditions. The contribution of species that actively respond to the $\mathrm{CO}$ vs. NO concentration modulation has been separated from that of species (the majority, i.e., reduced $\mathrm{Pd}$ ) that do not respond to the stimulation. The differentiation of signals with different kinetics, i.e., of different $\mathrm{Pd}$ species, is also enabled through the improvement of the signal-to-noise ratio. What remains to be verified is whether the observed processes are relevant to the NO reduction by CO [16]. Moreover, remembering that the particles size of $\mathrm{Pd}$ in the sample is of ca. $5 \mathrm{~nm}$ and that on average $\mathrm{Pd}$ remained in the reduced state all over the modulation experiment, it seems clear that only a small portion of $\mathrm{Pd}$ is actively involved in the $\mathrm{CO}+\mathrm{NO}$ reaction and thus that the PSD allows looking selectively at potentially active species and at surface phenomena.

\subsection{CO Oxidation on $\mathrm{Pt} / \mathrm{Al}_{2} \mathrm{O}_{3}$}

In the second example, a reduced $2 \mathrm{wt} \% \mathrm{Pt} / \mathrm{Al}_{2} \mathrm{O}_{3}$ catalyst was subjected to ten $\mathrm{CO}$ vs. $\mathrm{O}_{2}$ pulses at $463 \mathrm{~K}$ while QuickEXAFS spectra were collected at the $\mathrm{Pt}_{3}$-edge. CO is reported to significantly perturb the X-ray absorption near edge region of the $\mathrm{Pt}_{3}$-edge and $\mathrm{CO}$ adsorption on $\mathrm{Pt}$ typically results in intensification and broadening of the whiteline and shift to higher energy [30]. Inspection of the time-resolved spectra of Fig. 4(a) reveals an obvious change at the Pt whiteline. Other spectral changes can be captured only in the averaged spectra, which reveal a slight broadening of the whiteline and increased features above the whiteline during the modulation experiment. On the other hand Fig. 4(b) shows that the state of the $\mathrm{Pt} / \mathrm{Al}_{2} \mathrm{O}_{3}$ catalyst prior to the modulation experiment is largely reduced, because of the relatively large $\mathrm{Pt}$ particles (see Experimental) and the reductive pre-treatment $(673 \mathrm{~K})$. PSD (Eq. 1) of the (ca. 2400) time-resolved spectra provides the set of phase-resolved spectra $\left(\varphi^{\mathrm{PSD}}=0-80^{\circ}\right)$ shown in Fig. 5. In this case, the energy scale is reported relative to the $\mathrm{Pt}_{3}$-edge position. The signals responding to the $\mathrm{CO}$ vs. $\mathrm{O}_{2}$ stimulation are well separated from all other features and exhibit the second-derivative shape typical of difference spectra. The spectra also exhibit 

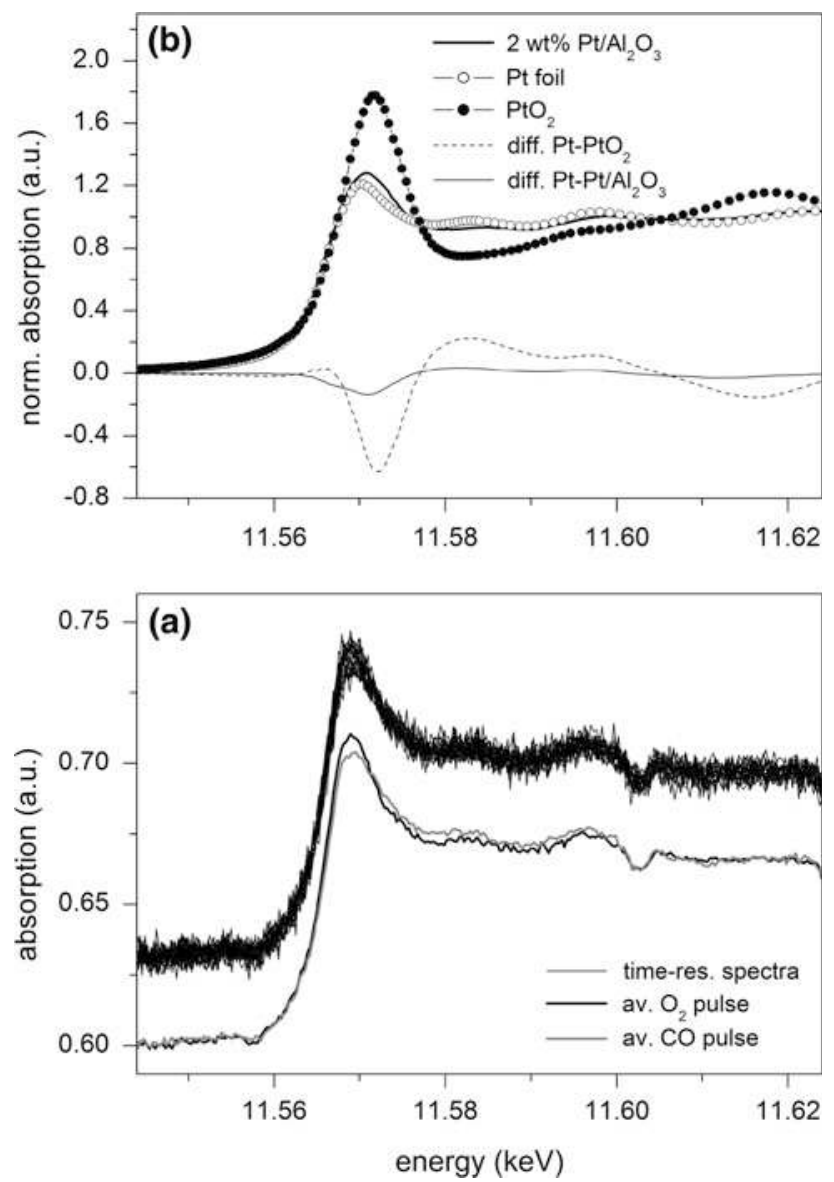

Fig. 4 a Time-resolved QuickEXAFS spectra collected at the $\mathrm{Pt}_{3_{3}-}$ edge and average spectra during the 5 vol\% $\mathrm{CO}$ vs. 5 vol\% $\mathrm{O}_{2}$ modulation experiment on reduced $2 \mathrm{wt} \% \mathrm{Pt} / \mathrm{Al}_{2} \mathrm{O}_{3}$. b The spectra of the $\mathrm{Pt}$ foil, $\mathrm{PtO}_{2}$ and of the $2 \mathrm{wt} / \mathrm{Pt} / \mathrm{Al}_{2} \mathrm{O}_{3}$ sample in the capillary reactor are shown together with the difference spectra $\mathrm{Pt}_{\text {foil }}-\mathrm{PtO}_{2}$ and $\mathrm{Pt}_{\text {foil }}-\mathrm{Pt} / \mathrm{Al}_{2} \mathrm{O}_{3}$. Conditions: $463 \mathrm{~K}, T=120 \mathrm{~s}, 10$ modulation periods

excellent signal-to-noise ratio and do not require smoothing to remove random noise.

The phase-resolved spectra exhibit the changes of the whiteline and at energies directly above it. The whiteline

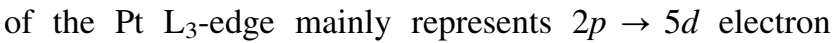
transitions; therefore, an intense whiteline is indicative of unoccupied $5 d$ orbitals and thus of an oxidized state of Pt. The larger the whiteline, the more oxidized the sample is. In Fig. 5, when the whiteline is at its minimum, the feature at ca. $+14 \mathrm{eV}$ above $E_{0}$ (ca. $+9 \mathrm{eV}$ above the whiteline) is at its maximum value, thus the two signals are anti-correlated. The feature at $+14 \mathrm{eV}$ can be assigned to the contribution of coordinated $\mathrm{CO}$ to Pt particles [30-33]. Therefore, the phase-resolved spectra show that reduction-oxidation is occurring through the repeated $\mathrm{CO}$ vs. $\mathrm{O}_{2}$ pulsing and additionally reveal adsorption-reaction of $\mathrm{CO}$.

To confirm the presence of adsorbed $\mathrm{CO}$, identical pulse sequences were performed in an independent
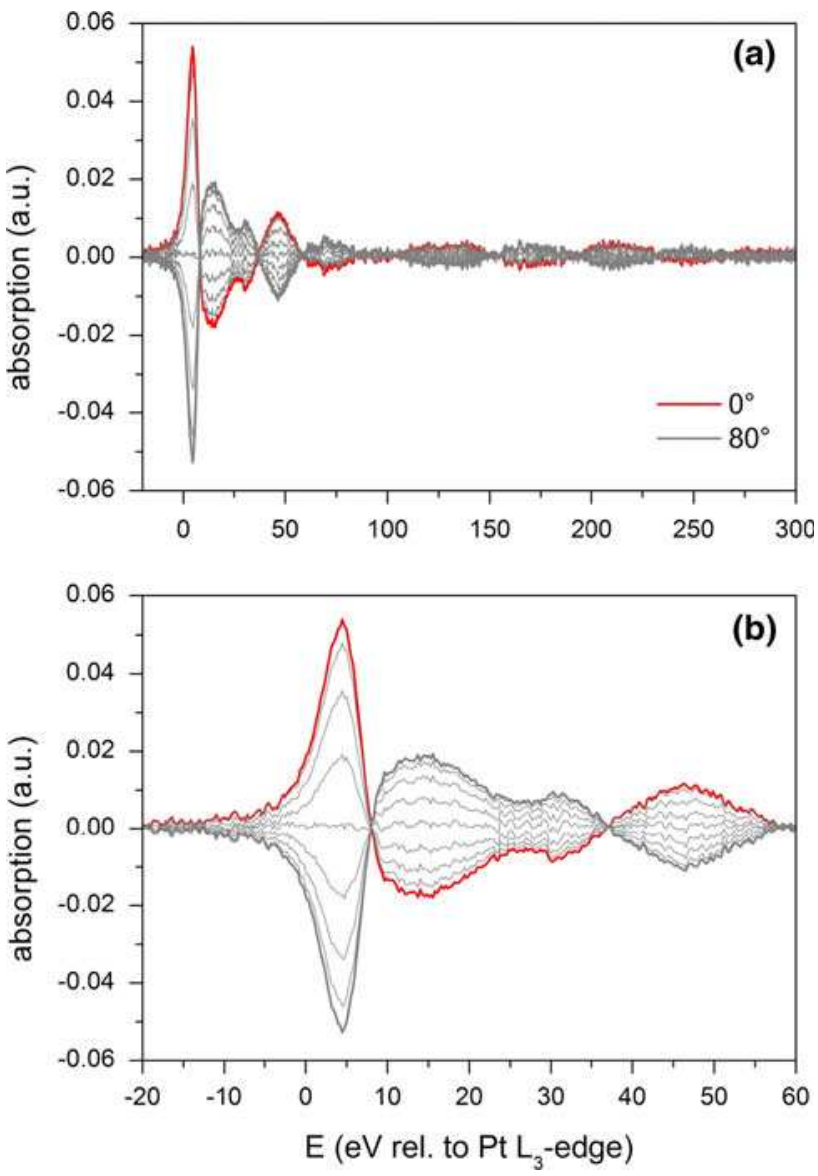

Fig. 5 a Phase-resolved spectra $\left(\varphi^{\mathrm{PSD}}=0-80^{\circ}\right)$ obtained from the 5 vol $\%$ CO vs. 5 vol $\% \mathrm{O}_{2}$ modulation experiment on reduced 2 wt $\%$ $\mathrm{Pt} / \mathrm{Al}_{2} \mathrm{O}_{3}$. b Enlargement of the -20 to $+60 \mathrm{eV}$ energy region

DRIFTS experiment in a different type of reactor cell but under otherwise identical conditions of flow and gas concentration. Figure 6 shows the time-resolved IR spectra collected during such an experiment. Intense signals of a-top CO are observed at 2082 and $2069 \mathrm{~cm}^{-1}$ and are accompanied by bridge adsorbed $\mathrm{CO}$ $\left(1840 \mathrm{~cm}^{-1}\right)$. Adsorbed CO is completely and instantaneously removed by the subsequent oxygen pulse. On its turn, $\mathrm{CO}$ rapidly adsorbs after admittance to the cell. IR and MS data show that at the $\mathrm{CO} \rightarrow \mathrm{O}_{2}$ and $\mathrm{O}_{2} \rightarrow \mathrm{CO}$ switches, $\mathrm{CO}_{2}$ production experiences a maximum. At the $\mathrm{O}_{2} \rightarrow \mathrm{CO}$ switch, $\mathrm{CO}_{2}$ production persists for longer time, whereas, at the $\mathrm{CO} \rightarrow \mathrm{O}_{2}$ switch it is more intense but shorter. Beside adsorbed $\mathrm{CO}$ on $\mathrm{Pt}$, carbonate-like species are observed at $1652 \mathrm{~cm}^{-1}$, which follow the time-dependence of the product $\mathrm{CO}_{2}$.

The temporal response of the whiteline in the QuickEXAFS experiment is reported in Fig. 7 in comparison with the MS data. The whiteline has maximum amplitude during the oxygen pulse and minimum amplitude during the CO pulse. The different reactor compared to the DRIFT 


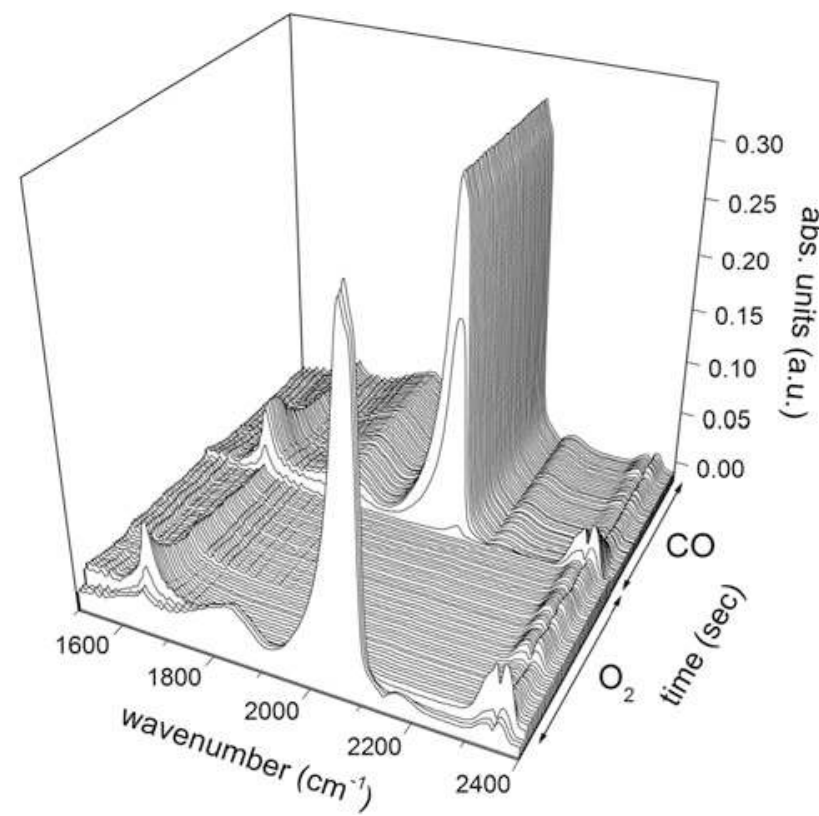

Fig. 6 DRIFT spectra collected during the 5 vol $\%$ CO vs. 5 vol\% $\mathrm{O}_{2}$ modulation experiment on reduced $2 \mathrm{wt} \% \mathrm{Pt} / \mathrm{Al}_{2} \mathrm{O}_{3}$. Conditions: $573 \mathrm{~K}, T=120 \mathrm{~s}$

experiment causes the profiles of the gas species to deviate. The advantage of the reactor cell of the previous case study $\left(\mathrm{Pd} / \mathrm{Al}_{2} \mathrm{O}_{3}\right)$ to collect synchronous EXAFS/IR data becomes relevant here and is exemplified by the identical profiles of the gas-phase $\mathrm{CO}_{2}$ signal of Fig. 3 . In the capillary reactor, the amplitude changes at the $\mathrm{CO}$ vs. $\mathrm{O}_{2}$ and $\mathrm{O}_{2}$ vs. $\mathrm{CO}$ switches are sharp. These changes correspond to spikes of $\mathrm{CO}_{2}$ production which are larger at the $\mathrm{O}_{2}$ vs. $\mathrm{CO}$ switch than at the $\mathrm{CO}$ vs. $\mathrm{O}_{2}$ switch. This is maintained throughout the DRIFT experiment. Therefore, catalytic activity appears generally larger when the state of Pt changes from partially oxidized to reduced. This is in good agreement with reports showing the requirement for partially oxidized $\mathrm{Pt}$ to best run the reaction [30, 34-36]. Additional pulse experiments with different pulse size and pulse compositions should be carried out to provide substantial confirmation of these preliminary results.

However, this experiment shows the detailed level of molecular information that could be achieved in a measurement at the $\mathrm{Pt} \mathrm{L}_{3}$-edge, which in principle allows monitoring the response of the precious metal to adsorbates. The phase-resolved spectra of Fig. 5 are the signature of a surface process that is hardly visible in the time-resolved spectra. Access to the temporal changes of CO surface coverage could be in principle obtained very directly from the phase-resolved spectra when having suitable spectra of reference states of the catalyst [32].

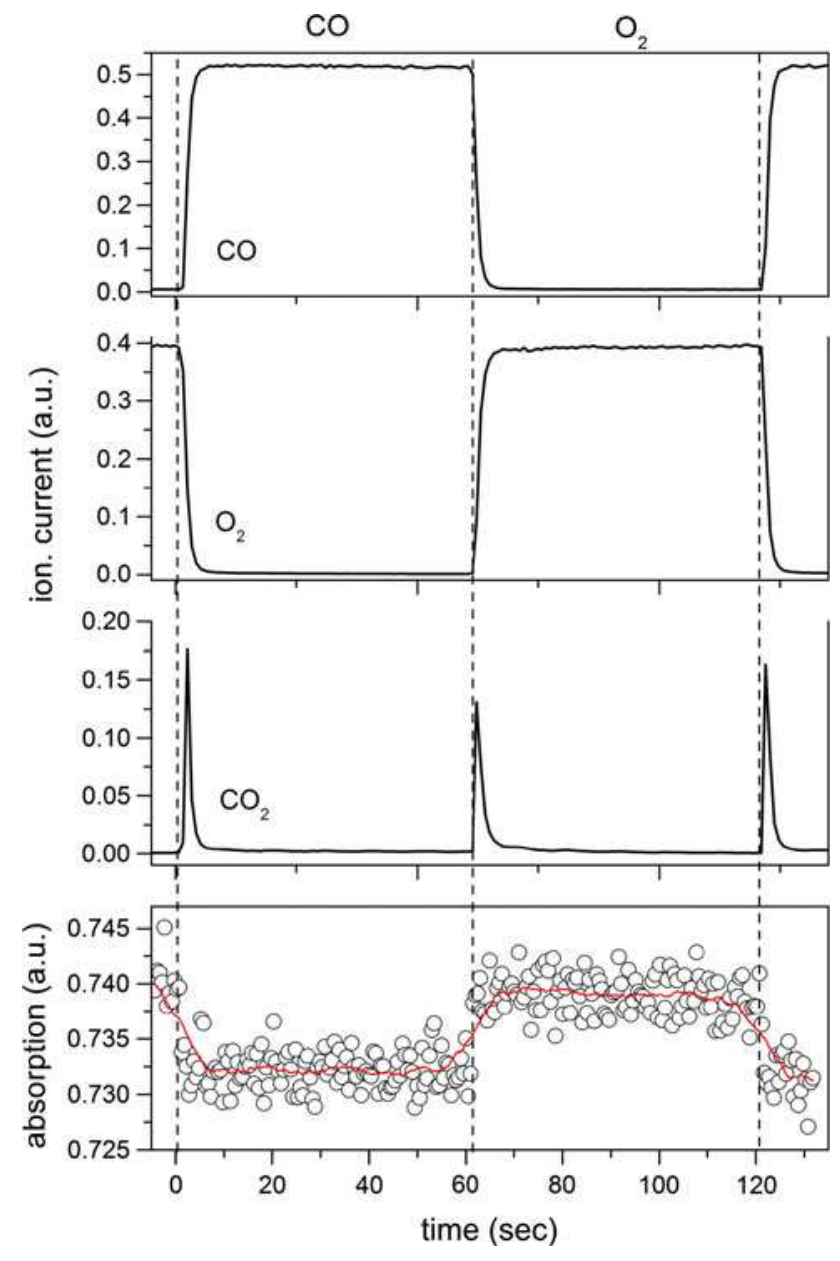

Fig. 7 Online $\mathrm{MS}$ response of $\mathrm{CO}, \mathrm{O}_{2}$ and $\mathrm{CO}_{2}$ and temporal evolution of the $\mathrm{Pt}$ whiteline during the 5 vol\% $\mathrm{CO}$ vs. 5 vol\% $\mathrm{O}_{2}$ modulation QuickEXAFS experiment on reduced $2 \mathrm{wt} \% \mathrm{Pt} / \mathrm{Al}_{2} \mathrm{O}_{3}$

\subsection{Outlook}

The two examples shown above demonstrate that modulation excitation spectroscopy has the potential to impart a bulk technique such as EXAFS with some form of surface sensitivity. In the case study of Pd those aspects that are purely surface or selvedge in nature (low level oxidation and reduction) can be isolated from instances where the bulk of the supported nano-particle participates in the chemistry (transient storage of atomic C). This has wide ranging implications for the study of catalysts of all denominations, not just those that involve supported metal nano-particles. Efforts by us and other groups $[37,38]$ aim at applying the method in a more systematic way and to add other synchrotron-based techniques, XRD and emission spectroscopy for example, to those to which it can be applied. To this end, it should be noted that Eq. 1 reports a generic energy scale $(e)$. Therefore, in principle PSD can be applied to any method providing the requisite levels of 
reversibility of the system under study: the underlying principles and mathematics that describe this approach are in no way prescriptive in this sense. This is part of the unexplored potential of MES.

For heterogeneous catalysts, the potential of the method is expected to be enormous in the case of the analysis of $\mathrm{L}_{3}$-edges, as for the $\mathrm{Pt}$ case study. $\mathrm{L}_{3}$-edges in principle provide far more direct access to information about adsorbates as in the $\Delta \mu$-XANES [33] and the HERFD-XAS [39] approaches. Furthermore, MES experiments at $3 d$ transition metal pre-edges will be a challenging task for the next future. Such analysis will most likely add insight into red-ox processes involving bulk metal oxides as supports or catalysts and will contribute to make XAS surface sensitive in the way we have described here. For example, based on time-resolved XAFS analysis, without MES and PSD, it was shown that the electronic and structural transformations at $\mathrm{Ce}$ and $\mathrm{Zr}$ sites during the oxygen storage-release process are not synchronized with each other in the $\mathrm{CeO}_{2}-\mathrm{ZrO}_{2}$ solid solution [40].

Finally, systematizing how we can effectively extract the information that is undoubtedly lying within the phaseresolved spectra of Figs. 2 and 5 in a more conventional EXAFS approach is a major challenge that has yet to be addressed. Typically, the XANES region can be scanned quickly and in a single hit relatively easily, in some senses. However, XANES is still not as well understood or codified as EXAFS. The majority of the literature dealing with time-resolved works using XANES is 'limited' to statements about 'oxidized' or 'reduced' states, thus with qualitative structural insights. Doing the same kind of timeresolved experiments with EXAFS is a much more difficult issue [20, 41], yet it is EXAFS that contains the more readily comprehendible structural data.

What is needed whether dealing with XANES or EXAFS is to always have recourse to good and relevant standard measurements. As we are always relying on differences, and it cannot be guaranteed that only bond lengths are changing (as is ubiquitously the case wherever differential XAS techniques are currently applied) this is a prerequisite to getting into what the differences might mean: it is all in there but getting it out reliably is not trivial even with suitable standards. If this can be achieved, a route is obtained into very sensitively assessing structural changes in the catalyst under study. The sensitivity it is ended up with will be probably over an order of magnitude better compared to conventional analysis by both XANES and EXAFS.

Acknowledgments The authors kindly acknowledge the financial support of Empa, Umicore and the Swiss National Science Foundation (SNF). Dr. M. Santhosh Kumar, A. Eyssler and O. Korsak, are thanked for their valuable help during beam time and Dr. R. Wirz and Dr. E. Kleymenov for editing precious Matlab scripts. The European
Synchrotron Radiation Facility (ESRF, Grenoble) and the Swiss Light Source (SLS, PSI Villigen) are thanked for allocating beam time for these experiments.

\section{References}

1. Weckhuysen BM (2004) In situ spectroscopy of catalysts. American Scientific Publisher, Stevenson Ranch

2. Banares M (2006) Catal Today 113:48

3. Tibiletti D, Goguet A, Reid D, Meunier FC, Burch R (2006) Catal Today 113:94

4. Efstathiou AM, Verykios XE (1997) Appl Catal A 151:109-166

5. Burch R (2003) Top Catal 24:97

6. Silveston P, Hudgins RR, Renken A (1995) Catal Today 25:91

7. Heck RM, Farrauto RJ, Gulati ST (2009) Catalytic air pollution control: commercial technology. Wiley, Hoboken

8. Baurecht D, Fringeli UP (2001) Rev Sci Instrum 72:3782

9. Urakawa A, Baiker TBA (2008) Chem Eng Sci 63:4902

10. Bürgi T, Baiker A (2002) J Phys Chem B 106:10649

11. Gisler A, Bürgi T, Baiker A (2003) PCCP 5:3539

12. Wirz R, Bürgi T, Baiker A (2003) Langmuir 19:785

13. Urakawa A, Bürgi T, Baiker A (2003) J Phys Chem B 107:13061

14. Bürgi T (2005) J Catal 229:55

15. Burgi T, Baiker A (2006) Adv Catal 50:227

16. Ferri D, Santhosh Kumar M, Wirz R, Eyssler A, Korsak O, Hug P, Weidenkaff A, Newton MA (2010) PCCP 12:5634

17. Becker E, Carlsson PA, Grönbeck H, Skoglundh M (2007) J Catal 252:11

18. Newton MA, di Michiel M, Kubacka A, Fernandez-Garcia M (2010) J Amer Chem Soc 132:4540

19. Becker E, Carlsson PA, Kylhammar L, Newton MA, Skoglundh M (2011) J Phys Chem C 115:944

20. Stoetzel J, Lutzenkirchen-Hecht D, Frahm R, Kimmerle B, Baiker A, Nachtegaal M, Bauer MJ, Grunwaldt JD (2009) J Phys: Conf. Ser 190

21. Newton MA (2009) Topics Catal 52:1410

22. Newton MA (2007) J Synchr Rad 14:372

23. Grunwaldt JD, Caravati M, Hannemann S, Baiker A (2004) PCCP 6:3037

24. Ressler T (1998) J Synchr Rad 5:118

25. Newton MA, Belver-Coldeira C, Martinez-Arias A, FernandezGarcia M (2007) Nature Mater 6:528

26. Almusaiteer K, Chuang SSC (1998) J Catal 180:161

27. Chilukoti S, Gao F, Anderson BG, Niemantsverdriet JW, Garland M (2008) PCCP 10:5510

28. Teschner D, Borsodi J, Wootsch A, Revay Z, Havecker M, KnopGericke A, Jackson SD, Schlogl R (2008) Science 320:86

29. Bowker M, Counsell J, El-Abiary K, Gilbert L, Morgan C, Nagarajan S, Gopinath CS (2010) J Phys Chem C 114:5060

30. Singh J, Alayon EMC, Tromp M, Safonova OV, Glatzel P, Nachtegaal M, Frahm R, van Bokhoven JA (2008) Angew Chemie Int Ed 47:9260

31. Stakheev AY, Zhang Y, Ivanov AV, Baeva GN, Ramaker DE, Koningsberger DC (2007) J Phys Chem C 111:3938

32. Guo N, Fingland BR, Williams WD, Kispersky VF, Jelic J, Delgass WN, Ribeiro FH, Meyer RJ, Miller JT (2010) PCCP $12: 5678$

33. Ramaker DE, Koningsberger DC (2010) PCCP 12:5514

34. Hendriksen BLM, Frenken JWM (2002) Phys Rev Lett 89:046101

35. Urakawa A, Bürgi T, Schläpfer HP, Baiker A (2006) J Chem Phys 124:054717

36. Alayon EMC, Singh J, Nachtegaal M, Harfouche M, van Bokhoven JA (2009) J Catal 263:228 
37. Urakawa A, van Beek W, Monrabal-Capilla M, Galan-Mascaros JR, Palin L, Milanesio M (2011) J Phys Chem C 115:1323

38. Chernyshov D, van Beek W, Emerich H, Milanesio M, Urakawa A, Viterbo D, Palin L, Caliandro R (2011) Acta Cryst A 67:327

39. Safonova O, Tromp M, van Bokhoven JA, de Groot FMF, Evans J, Glatzel P (2006) J Phys Chem B 110:16161
40. Yamamoto T, Suzuki A, Nagai Y, Tanabe T, Dong F, Inada Y, Nomura M, Tada M, Iwasawa Y (2007) Angew Chemie Int Ed 46:9253

41. Pascarelli S, Mathon O (2010) PCCP 12:5535 